\title{
Consumo midiático, localismos e cosmopolitismos: a série brasileira Coisa mais linda
}

\section{Clarice Greco' Gustavo Souza² Simone Luci Pereira ${ }^{3}$}

\section{Resumo}

Este artigo traz reflexões sobre novas formas de consumo midiático, como as plataformas de Video on Demand a exemplo da Netflix, abordando o localismo nas produções nacionais e o cosmopolitismo proporcionado pela transmissão de conteúdo para públicos globais. A conceituação teórica é ancorada em autores que discutem o consumo cultural (GARCÍA CANCLINI, 2004), a nacionalização da ficção televisiva (LOPES, 2004) e a memória como recurso no audiovisual (MACDOUGALL, 1998). Em seguida, discorremos brevemente sobre as séries nacionais produzidas pela Netflix Brasil até o final de 2019, a fim de ilustrar as primeiras experiências da produtora e a tendência a certos tipos de narrativas ou gêneros. Por fim, analisamos os elementos nacionais e a relação com a memória presentes na série Coisa Mais Linda (Netflix Brasil, 2019). A análise da série parte da ideia de "promessa de sentido" (JOST, 2008) para, a seguir, se deter na narrativa com foco nas personagens (JOLY, 1996). Como resultado argumentamos que é possível perceber na série elementos de uma 'brasilidade' demarcada para conquista de público internacional e o uso de uma temporalidade passada para discutir questões do presente.

\section{Palavras-chave}

Consumo Midiático; Netflix; Feminismo; Memória; Coisa Mais Linda. 


\section{Media consumption, localisms and cosmopolitisms: the Brazillian series Most Beautiful Thing}

\section{Clarice Greco' Gustavo Souza² Simone Luci Pereira ${ }^{3}$}

\section{Abstract}

This article reflects upon the new forms of media consumption, such as the Video on Demand platforms (we will use Netflix as an example), addressing elements of localism in national productions and the cosmopolitanism provided by the transmission of regional content to global audiences. The theoretical approach is anchored in authors who discuss cultural consumption (GARCÍA CANCLINI, 2004), the nationalization of television fiction (LOPES, 2004) and memory as audiovisual resource (MACDOUGALL, 1998). Then, we present a brief description of the national series produced by Netflix Brazil until the end of 2019, in order to illustrate the producer's previous experiences and the tendency to some kind of narratives and genres. At last, we analyze the national elements and the relation with memory shown in the series 'Most Beautiful Thing' (Netflix Brazil, 2019). The analysis of the series starts with the idea of "promise of sense" (JOST, 2008) and follows focusing on the narrative, especially the characters (JOLY, 1996). As a result, we argue that, in the analysis of the series Coisa Mais Linda (Netflix Brazil, 2019), it is possible to see elements of a 'Brazilianness' created for an international audience and the use of a past temporality to discuss issues of the present.

\section{Keywords}

Media Consumption; Netflix; Memory; Feminism; Most Beautiful Thing 
No campo da Comunicação, a discussão sobre consumo midiático estabelece diálogo importante com as Ciências Sociais. Nesta perspectiva, o consumo compreende as lógicas envolvidas nas práticas de produção e recepção de materialidades e imaginários em que produtos, símbolos e marcas são vistos em sua dimensão simbólica e cultural ajudando a criar distinções e sistemas classificatórios, estilos de vida e identidades, funcionando como vetor de formas de inserção, pertencimento e cidadania (GARGÍA CANGLINI, 2004; DOUGLAS; ISHERWOOD, 2004; MCGRACKEN, 2003).

Nesse contexto, empresas multinacionais mesclam as fronteiras entre o nacional e o global, comercializando produtos de culturas diversas. A circulação global de produtos audiovisuais não é uma novidade, dado que as telenovelas são exportadas desde a década de 1970 [1] e a chegada da TV a cabo ao Brasil ampliou o fluxo de conteúdos estrangeiros. No entanto, atualmente as plataformas de Video on Demand trouxeram outra dimensão para o consumo desses produtos. É o caso da Netflix, produtora e distribuidora de conteúdos audiovisuais via streaming. De origem norte-americana, a Netflix consolidou transformações nos modos de consumo e circulação de filmes e séries, intercalando o global (pela transmissão de produtos estrangeiros) e o local (por meio de produção nacional própria).

No Brasil, a oferta de conteúdo nacional pela Netflix explora temas da cultura local visando também o público internacional. É o caso da série Coisa Mais Linda, que intercala elementos da cultura brasileira, como a bossa nova, o eixo Rio-São Paulo e Iemanjá, e temas universalizáveis, como a desigualdade social e o papel da mulher na sociedade. Com esse fim, ela faz uso do cenário dos anos 1950 para tratar de temas atuais, recorrendo ao passado para se referir ao presente.

Neste trabalho, pretendemos analisar a série para perceber como ela faz uso do cenário dos anos 1950 para tratar de temas atuais, recorrendo ao passado para se referir ao presente. Para isso, seguimos inicialmente a recomendação de Jost quando postula que a análise de qualquer programa televisivo requer apreender a "promessa de sentido" (JOST, 2008, p. 197) em que se apoia. Identificado esse aspecto, passamos à seleção das sequências da série em que se sobressaem tal promessa numa análise mais detida na imagem e no som. Isso implica, segundo Joly (1996), observar o eixo narrativo e o papel que os personagens exercem na trama de modo a identificar para qual discussão a análise aponta, criando, assim, um horizonte de expectativa sobre os potenciais imagéticos e discursivos da série. 
García Canclini (2004), extrapolando a ideia de necessidade e instrumentalidade dos bens, desenvolveu importante conceituação acerca do consumo cultural que pode ser compreendido como estando vinculado aos processos gerais de apropriação e usos dos produtos, mas em que o valor simbólico prevaleceria sobre os valores de uso/troca. A partir desta noção de consumo cultural, Toaldo e Jacks (2013) vêm pensando sobre o consumo midiático como uma vertente do primeiro, especificamente articulado ao uso e as apropriações da produção cultural midiática - sejam os grandes meios como televisão, rádio, jornal, revista, internet, sites, blogs, celulares, tablets, sejam os produtos/conteúdos oferecidos por esses meios como telenovelas, filmes, séries, músicas, informações, etc.

Esta noção de consumo midiático nos orienta na maneira como pensamos os usos e apropriações bem como as lógicas comerciais e institucionais do consumo da Netflix na atualidade em tempos de cultura da convergência (JENKINS, 2008). Mostra-se importante compreender como os sujeitos consomem as mídias (neste caso as digitais), por quais suportes ou meios, quais produtos/conteúdos bem como as maneiras pelas quais as utilizam no cotidiano, em quais contextos (lugares, maneiras, rotinas), pois isso afeta a experiência do consumo e as impressões que os indivíduos têm de si, da sociedade, do mundo. Um consumo midiático, assim, como dimensão para compreender processos sociais, culturais, econômicos, políticos, afetuais [2] mais amplos.

Segundo Castellano e Meimaridis (2018) existem hoje variadas possibilidades de acesso ao consumo televisivo, desde a recepção tradicional em TV aberta até os sistemas streaming (onde se contextualiza a Netflix). Isso permite a possibilidade de construção de múltiplos regimes de espectatorialidade da TV e das séries, criando temporalidades paralelas no consumo e nos usos de um mesmo produto cultural. Esta característica se acentua e se mostra mais explicitamente no consumo de ficção seriada, formato que, segundo as autoras, parece sofrer maior impacto com os novos modelos tecnológicos de produção e distribuição, apresentando formas de consumo como as maratonas de séries - ou binge-watching - cada vez mais populares. O fato de os produtores da Netflix adotarem estratégias como a disponibilização das temporadas das séries de uma só vez no serviço de streaming, acabam por favorecer consumos midiáticos ou formas de recepção que tanto podem ser cadenciados (como nos formatos tradicionais de TV), coletivos em comunidades de fãs, individuais ou em maratonas. Estas formas de recepção e consumo implicam em formas diferenciadas 
de fruição e apropriação, mostrando-se um objeto analítico importante de ser compreendido na cultura midiática.

Com estas novas dinâmicas de produção, circulação e consumo nos meios digitais, vai se esboçando o que Silva (2014) chama de uma "cultura das séries", resultado da intensa atuação e articulação de novas dinâmicas espectatoriais reunidas em torno de três vetores: 1.) o desenvolvimento de novos modelos narrativos em meio à reconfiguração de modelos clássicos, ligados a gêneros estabelecidos como a sitcom, o melodrama e o policial; 2.) o contexto tecnológico em torno do digital e da internet, que impulsionou a circulação das séries em nível global, para além do modelo tradicional de circulação televisiva; 3.) as formas de consumo desses programas, tanto na dimensão espectatorial do público (comunidades de fãs, estratégias de engajamento), como na criação de espaços noticiosos e críticos, focados nas séries de televisão.

Retomando Silva (2014), temos que, com estes novos modos de distribuição de séries e outros conteúdos, deixa-se gradativamente de falar em exportação, para se falar de circulação de produtos televisivos. Segundo o autor,

num primeiro momento, pode parecer a simples mudança de um
paradigma industrial do capitalismo (com os bens materiais ocupando
o grosso dos proventos) para um capitalismo pós-industrial, cognitivo,
em que os bens simbólicos e culturais circulam transnacionalmente
com mais fluidez, num circuito virtual extremamente complexo e
intrincado. Não se pode adjurar aqui a superação - pelo menos não
imediatamente, como os dados culturais e econômicos indicam - de um
modelo de televisão nacional e em fluxo, para um modelo transnacional
e em rede. Essa superação, se e quando ocorrer, será fruto de um longo e
matizado processo de disputas materiais e simbólicas (SILVA, 2014, p. 247).

Nesse sentido, o consumo de séries não se restringe a comunidade de fãs em torno de obras específicas, mas aponta para uma formação de repertórios que se mostram em suas lógicas espectatoriais transnacionais e cosmopolitas. Como nos lembra Appadurai (2004), na modernidade tardia as migrações e a comunicação eletrônica colocam em circulação fluxo de pessoas, imagens, imaginários, subjetividades, materialidades, alterando o que ele chama de "obra da imaginação" global e midiática, que pode servir como local de negociação e contestação entre as formas globais de vida e as experiências locais de modernização. Conformam-se aí comunidades de sentido, gostos e estilos de vida para além dos limites do Estado-Nação por via das formas de consumo cultural (GARCÍA CANCLINI, 2004) ou midiático e onde se articulam, se entrecruzam e negociam espaço diferentes gostos, lógicas, imaginários e experiências locais/globais. A cultura das séries, conectada a uma "telefilia transnacional” (SILVA, 2014) parece se materializar neste contexto apontado por Appadurai, no qual fluxos 
de imagens, textos e sensações mediatizados colaboram na construção de novas ordens de produção de subjetividades, identidades e pertencimentos. Cosmopolitismos que se consubstanciam no consumo de séries (em seus imaginários, materialidades, experiências acionadas) deslocando o debate a respeito das formas de vida cosmopolitas como estando ligados apenas aos deslocamentos concretos, mas antes, mediadas por uma disposição mental (HANNERZ, 1990; DELANTY, 2008), em formas de manejar e negociar sentidos, que revelam formas de se envolver com o Outro.

Assim, as tecnologias precisam ser compreendidas não apenas em si mesmas, mas nos usos que fazemos dela, alterando sensoriuns, sensibilidades, maneiras de estar juntos, formas de identificação individual e coletiva, entre outros aspectos. Martín-Barbero (2004), numa apropriação das leituras de Simmel e Benjamin sobre a experiência da Modernidade, nos oferece a noção de tecnicidade, como sendo um (des)organizador perceptivo, referindo-se ao estatuto social e cultural da técnica, escapando de uma análise meramente instrumental, mas compreendendo as técnicas naquilo que ela modifica ou altera os saberes, as práticas, os modos de sentir e pensar.

O consumo midiático ligado às séries na Netflix nos aponta para este contexto cultural e tecnológico sui generis em que a facilidade de encontrar e assistir séries de muitos lugares do mundo, inclusive de outras épocas, assinala novas formas de espectarorialidade, temporalidades e espacialidades, possibilitando assistir "qualquer coisa a qualquer hora em qualquer lugar", slogan da Netflix do qual nos lembra Saccomori (2015) e que oferece um catálogo virtual de bilhões de horas de conteúdo audiovisual, quase como uma audiovideoteca infinita, para lembrar da biblioteca infinita e labiríntica de J.L. Borges. Nesta audiovideoteca infinita, telas conectadas a "inúmeros hiperlinks apontam para um ambiente multitarefas e multiplataforma perante o qual redimensionamos nossa atenção e nossas funções espectatoriais”(SILVA, 2014, p. 248).

\section{Brasil: um mercado de ficção nacional}

A iniciativa da Netflix de produzir séries nacionais é uma estratégia para expansão de fronteiras e conquista de novas audiências. No Brasil, as séries originais Netflix unem-se ao histórico de crescente nacionalização da produção televisiva, ainda que sob influência de modelo norte-americano. A TV brasileira como conhecemos hoje tem raízes no modelo estadunidense de televisão privada e geralista, que exportou para o Brasil programas, formatos e tecnologia. Ainda que existam diferenças históricas entre a influência internacional na TV brasileira e o modelo econômico da Netflix, o que importa para este artigo é posicionar as estratégias de internacionalização em 
um contexto de constante nacionalização da produção.

Ao longo dos anos, apesar de tentativas de abertura à importação, a ficção televisiva contou com crescente índice de nacionalização, enquanto expandia o mercado interno. Assim, estimulou a formação de uma capacidade de televisão nacional que desenvolveu não só uma vasta produção, mas também uma apropriação peculiar do gênero (LOPES, 2004).

A brasilidade da TV se fazia perceptível desde a década de 1980 [3] e chamou a atenção de pesquisadores como Straubhaar (1984). O autor fez um diagnóstico do cenário televisivo brasileiro no qual contrapôs nossa realidade com a suposição de que países do terceiro mundo seriam dependentes de sistemas das nações mais desenvolvidas, com importação de programas ou financiamento estrangeiro. Mais do que isso: a ficção televisiva brasileira não só é produzida nacionalmente como exportada para vários países.

Culturalmente, a centralidade da TV também influencia o conteúdo a ser exibido e, por consequência, o hábito de consumo dos telespectadores. Borges (2008, p.7) afirma que a televisão "apresenta-se como o espelho da sociedade, ou seja, a sociedade se vê através da televisão, pois ela the oferece uma representação de si mesma”. Isso porque a televisão reflete a sociedade e, ao representá-la, gera um laço que une todos aqueles que a assistem simultaneamente. Esse laço social é promovido em países com forte cultura televisiva, especialmente pela teledramaturgia. A América Latina se destaca nesse quesito, pela forte representação da televisão na sociedade e pela importância da ficção televisiva nessa cultura. Tal importância está altamente relacionada com a economia de indústria de televisão, mas também com a relevância cultural que adquiriu ao longo do tempo.

De acordo com Lopes (2003), a ficção televisiva brasileira tem o potencial de sintetizar o imaginário de uma nação, ou de se expressar como nação imaginada, pela qual a audiência forma uma comunidade com conceitos e premissas que controlam a aceitação do conteúdo televisivo que deve, por sua vez, encaixar-se nesses valores.

Apesar de ter público distinto daquele da TV aberta, a Netflix no Brasil se propõe a oferecer ficção televisiva para um público que entende do assunto. A população brasileira, por acompanhar telenovelas e séries desde seu surgimento, 'foi educado' para a ficção televisiva. Por isso, Wolton (1996) afirma que o público brasileiro é especialista em TV, do mesmo modo que Benjamin (1985) descreveu o público em relação ao esporte, por se engajar e emitir opiniões até mesmo sobre preceitos técnicos.

A Netflix se insere, portanto, em um mercado em que a ficção televisiva é predominantemente nacional. Isso não depõe, naturalmente, contra o sucesso dos filmes 
e das séries estrangeiras oferecidas pela plataforma, mas aponta para a importância de se analisar essas produções sob a ótica de uma cultura televisual. Nesse sentido, a Netflix não traz novos produtos, mas sim reincidências do mais clássico produto cultural brasileiro, sob nova forma de consumo.

\section{Netflix no Brasil}

O Brasil foi o segundo país a receber os serviços de streaming da Netflix fora dos Estados Unidos. A empresa, que iniciou como locadora de vídeos online em 1997 e passou a oferecer filmes por streaming em 2007, atuou por muito tempo apenas no território norte-americano. A primeira oferta internacional se deu em 2010, para o Canadá e, em 2011, a empresa expandiu para o mercado da América Latina. O Brasil foi o primeiro país da América Latina a inaugurar a oferta por streaming, e, portanto, o terceiro no mundo. No início, porém, enfrentaram dificuldades, uma vez que existia - e ainda existe - grande divisória digital no País. Ao longo dos últimos anos, o público interessado cresceu exponencialmente e hoje existem mais de 40 serviços de diferentes modalidades de VoD no Brasil (LOPES; GRECO, 2018).

Com o passar dos anos e do crescimento do consumo on demand, a Netflix ampliou sua audiência. A empresa não divulga oficialmente o número de assinantes fora dos EUA, mas segundo Erik Barmak, vice-presidente de conteúdo internacional da Netflix [4], o Brasil está entre seus três maiores mercados. Estima-se que os brasileiros representem 6\% a 7\% dos 117 milhões de assinantes no mundo, totalizando aproximadamente 8 milhões de assinantes no País. Com a crescente audiência, a Netflix percebeu um mercado fecundo e passou a investir também em produções originais. $\mathrm{O}$ executivo afirmou, ainda, haver demanda de brasileiros por mais conteúdo nacional [5].

A primeira série ficcional brasileira produzida pela Netflix foi $3 \%$, lançada em novembro de 2016, com segunda temporada em 2018 e terceira confirmada para 2019 [6]. A narrativa se passa em um futuro distópico, no qual 97\% da população vive na miséria e, todo ano, há um processo seletivo para jovens se unirem aos 3\% que vivem no conforto.

Em 2018, a Netflix lançou outras duas séries brasileiras: O Mecanismo [7], cuja trama é, segundo o diretor Padilha, inspirada livremente na Operação Lava Jato, e Samantha! [8], sobre uma ex-cantora e apresentadora infantil que passa a vida adulta em decadente busca pela fama.

Coisa Mais Linda é, portanto, a quarta série produzida no Brasil. A trama se passa 
no Rio de Janeiro dos anos 1950 e conta a história da paulistana Maria Luiza (Maria Casadevall) e suas três amigas. Filha de fazendeiros, ela migra para o Rio de Janeiro para abrir um restaurante com o marido, que lhe aplica um golpe ao desaparecer com todo o seu dinheiro. Depois disso, ela resolve abrir um bar onde a bossa nova seria o estilo musical principal. Maria Luiza se torna amiga de Adélia (Pathy Dejesus), que é empregada doméstica, negra, mãe solteira; Lígia (Fernanda Vasconcellos), amiga de infância de Maria Luiza, sonha em ser cantora, mas é casada com um político que almeja concorrer à prefeitura do Rio e reprova seu talento e Thereza (Mel Lisboa), cunhada de Lígia, jornalista da revista Ângela, voltada para o público feminino.

O título Coisa Mais Linda é uma homenagem à canção homônima de João Gilberto e Tom Jobim, de 1959. Ainda que a apresentação da série seja a temática da Bossa Nova, a trama aborda mais o esforço por reconhecimento das mulheres - com acertos e deslizes - do que propriamente o contexto musical da época.

Apostando no sucesso dessas produções originais, a Netflix anunciou ao menos outras seis produções nacionais de ficção para os próximos anos: O Escolhido, Cidades Invisíveis, Ninguém Tä Olhando, A Facção, Spectros e Sintonia [9]. Há, ainda, séries documentais, como Vai, Anitta e a animação adulta Super Drags. Os sucessivos anúncios de novas produções mostram, além do envolvimento do público brasileiro, uma provável rentabilidade dessas séries em mercados internacionais.

Apesar de a Netflix ser uma plataforma de streaming, serviço que tem sido referência em discussões teóricas sobre o avanço e as mudanças tecnológicas e culturais do nosso universo midiático, é possível perceber a estreita relação das produções da Netflix com o conteúdo televisivo habitual no Brasil. Assim como as costumeiras telenovelas e séries da TV aberta, apesar de variarem entre drama, suspense e policial, todas as séries da Netflix até o momento apresentam características do melodrama, gênero tradicional da TV brasileira. Além disso, todos os protagonistas das produções originais Netflix são interpretados por atores que já passaram por telenovelas da Globo, contribuindo pouco para a diversidade de atores e autores nos conteúdos audiovisuais. Em outras palavras, reforçam o status quo monolítico da produção brasileira.

Há que se ressaltar, ainda, a aspiração da empresa em conquistar audiência em outros países. A ficção televisiva brasileira é objeto de exportação há anos, tendo, portanto, público internacional cativo. Para isso, parece investir em narrativas com temática brasileira, mas que possam ser reconhecidas por outros países: a desigualdade social de $\% \%$; a corrupção em O Mecanismo, as subcelebridades em Samantha! e, finalmente, o empoderamento feminino ao pano de fundo da bossa nova em Coisa Mais Linda, que analisaremos em mais detalhes adiante. Poderíamos dizer que essas 
narrativas exploram as qualidades de uma 'brasilidade rentável', que retrate aspectos do Brasil para o mercado nacional, mas que tenha potencial de conquistar públicos estrangeiros.

\section{Coisa Mais Linda}

Na busca por conteúdo nacional, a Netflix lançou, em março de 2019, a série brasileira Coisa Mais Linda. No fluxo do trabalho coletivo e das produções independentes, o mérito da série é dividido: criada por Giuliano Cedroni e Heather Roth, foi produzida por Beto Gauss e Francesco Civita e dirigida por Caíto Ortiz, Hugo Prata e Julia Rezende.

Das quatro séries já lançadas pela empresa, a proposta temática de Coisa Mais Linda talvez seja a mais pautada em elemento puramente nacional: a bossa nova. No entanto, a música aparece mais como pano de fundo do que propriamente objeto ou personagem da trama. Como já dito, outras produções nacionais da Netflix tratam de temas significativos no Brasil - desigualdade, corrupção e cultura popular - porém passíveis de universalização - ou, ao menos, de maior generalização. Por sua vez, os temas e conflitos tratados em Coisa Mais Linda são tão brasileiros quanto o podem ser - porém, de um "Brasil para gringo ver". A bossa nova é o gênero musical brasileiro de maior exportação e presença no imaginário referente ao País, graças à Garota de Ipanema (composição de Tom Jobim, que não surpreende ao ser tema de abertura da série) e seu imensurável alcance. Estão presentes, ainda, os elementos tradicionais de uma série que se diz brasileira: o Rio de Janeiro, o samba, o morro.

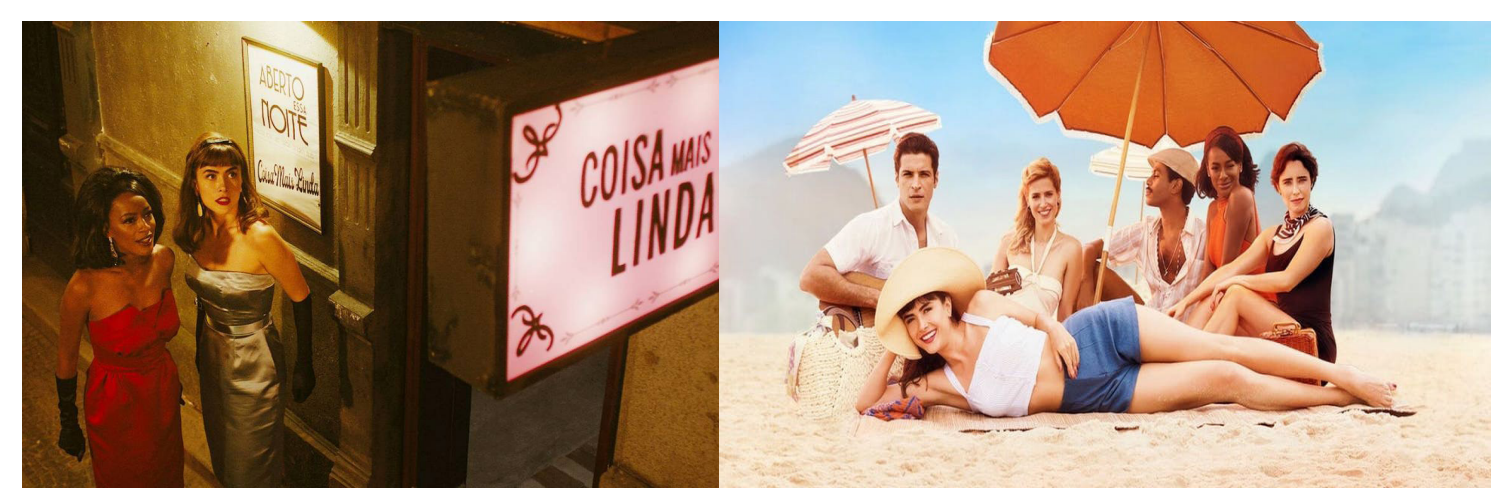

Figura 1 - Cena de Coisa Mais Linda e imagem de divulgação da série.

Fonte: Netflix Brasil (2019)

Coisa mais linda tem início em 1959 - momento de importantes mudanças na política e na música. No ano seguinte, o Rio de Janeiro deixaria de ser a capital do país 
com a inauguração de Brasília pelo então presidente Juscelino Kubitschek e a bossa nova já começava a ganhar contornos mais definidos no cenário musical carioca para, posteriormente, conquistar fama internacional. A retomada desse momento histórico servirá como pano de fundo para a série se concentrar em quatro personagens.

Como dito anteriormente, o consumo midiático institui, entre tantos aspectos, imaginários sobre pessoas, experiências, lugares. Há no Brasil uma disputa simbólica entre as cidades do Rio de Janeiro e de São Paulo, em que ambas se esforçam constantemente para provar suas qualidades e, por consequência, sua superioridade. A série parte de um imaginário já consolidado que associa o Rio de Janeiro à leveza, ao lazer e à natureza, enquanto São Paulo é vinculada à rigidez, ao conservadorismo e à obsessão pelo trabalho. "São Paulo é um tédio, não aguento mais que dois dias aqui", diz Lígia a Maria Luiza numa rápida passagem pela cidade onde encontra a amiga. Em meio a essa dualidade, é no Rio de Janeiro que Maria Luiza vislumbra a possibilidade de conquistar sua independência ao abrir seu próprio negócio (uma casa de shows), ou seja, é preciso deixar para traz o velho (São Paulo) para apostar no novo (Rio de Janeiro), ainda que isso implique deixar seu filho aos cuidados dos pais e gere uma rusga com o seu pai, que reprova sua decisão.

No plano interno da narrativa, há outros imaginários reforçados pela série. Um deles é o das favelas cariocas como lugares idílicos em que todos dançam ao som do samba, como se vê na sequência que Maria Luiza, levada por Chico (Leandro Lima), vai a uma favela pela primeira vez. Outro aspecto nesta direção é a referência a Iemanjá - orixá que representa o mar, segundo as religiões de matriz africana como candomblé e umbanda. Descontente com o abandono do marido, Maria Luiza se joga no mar durante um passeio de barco e lá no fundo se encontra com Iemanjá. A cena beira o surreal, mas é útil na construção de um possível imaginário religioso brasileiro. A rainha do mar também é retomada num momento em que, na véspera da inauguração do bar, uma chuva destrói tudo. Em meio ao que sobrou, Maria Luiza e Adélia encontram uma imagem de Iemanjá, que acaba servindo como um "sinal" para que não desistam.

No consumo midiático é possível perceber a elaboração de pertencimentos em que canções, videoclipes, e neste caso, séries, funcionam como "sistemas peritos” (AMAYA, 2004) servindo para articular, construir, elaborar sentidos de auto identidade, em ações individuais e coletivas, midiáticas e performativas. Imaginários e experiências pautados em séries, personagens, enredos, narrativas ajudam a construir sentidos, ligando (ou não) suas vidas àquelas narradas em séries ou filmes. Estas transformações envolvem, entre outros aspectos, uma relação intrínseca entre as 
tendências globalizantes financeiras/econômicas/políticas a eventos localizados na vida cotidiana e subjetiva - uma conexão dialética, complexa, entre o "extensional" e o "intencional" e a construção do eu como um projeto reflexivo (GIDDENS, 1999), em que os indivíduos encontram ou elaboram identidades entre as estratégias e opções fornecidas pelos sistemas peritos. Desse modo, os imaginários reforçados têm a intenção de criar pertencimento, muito embora estejam passíveis de discussão, pois, em alguma medida, eles reforçam clichês em relação aos espaços que retratam. Porém, julgamos mais proveitoso debater o discurso que alicerça a série e suas possíveis intenções. Para isso, partimos da hipótese que Coisa mais linda volta ao passado para falar do presente, sendo essa, portanto, a promessa de sentido a que nos referimos na introdução.

A ambientação da série na passagem da década de 1950 para 1960 permite a construção de uma memória que se ancora em valores, hábitos e estilos de vida que, segundo o que vemos, estavam em revisão (pelo menos no Rio de Janeiro, capital do país e vitrine do Brasil para o mundo), tais como a independência feminina, as questões classe e o racismo. Na prática, esses assuntos estão mais em voga no Brasil hoje do que há 60 anos. A volta ao passado serve, portanto, de pretexto para o debate sobre assuntos que ganhariam visibilidade, de fato, a partir da primeira década do século XXI, quando, no Brasil, negros, indígenas, LGBTs e pobres passaram a ser contemplados por políticas públicas estatais. Isso não implica que, na década de 1960, a igualdade de gênero, por exemplo, não fosse debatida, porém só em décadas posteriores o tema ganharia amplitude.

Desse modo, é importante verificar como se dá a representação audiovisual dessa memória. Como propõe MacDougall (1998), ela pode ocorrer por meio do visual, da fala, sons, gestos e movimentos, mas sem o intuito de criar uma "memória total" (MACDOUGALL, 1998, p. 241), pois é incerta e ambígua a conexão entre a construção do passado por meio de reminiscências e a construção da experiência atual.

A série parece demonstrar consciência em relação a essa ambiguidade a que se refere MacDougall ao privilegiar uma pauta feminista que vai do plot às tramas internas. Primeiramente, é preciso destacar que são quatro mulheres como figuras centrais. Todas elas precisam lidar com as adversidades e dilemas que condição feminina lhes impõe - condição esta que, em muitos casos, é utilizada para reforçar o lugar secundário reservado à mulher na condução do seu próprio destino. Desse modo, o pai de Maria Luiza insiste para que ela desista da casa de show para se casar com um rapaz que ele julga ideal para ela. Única mulher a trabalhar na redação da revista Ângela, Thereza é alvo de chacotas por parte dos colegas de trabalho. No início 
da série, Lígia coloca o marido sempre em primeiro plano e Adélia precisa lidar não somente com o peso de ser mãe solteira, mas também com o preconceito de classe e de raça. Ela se torna sócia de Maria Luiza no clube, mas é confundida com a empregada do lugar por ser negra.

As quatro personagens travam uma amizade que servirá também como rede apoio. Com isso, a série reforça a importância da sororidade em que a volta ao passado, empreendida pela narrativa, está envolta à importância dos afetos. Isto é, em Coisa mais linda, a construção da memória vai além da acumulação de informação, mas se reveste de condensação e deslocamento, pois, sem esse trabalho afetivo, mas também coletivo de objetivação da história com suas rejeições e pontos cegos, não haveria atualização, um novo investir do sabido no vivido e do vivido no sabido. Dito de outro modo, troca-se a fidelidade dos fatos e do contexto histórico para criar, de certa forma, uma memória sobre demandas recentes da sociedade brasileira, tais como a diminuição das diferenças entre homens e mulheres. Imagem e discurso articulam uma dialética entre passado e presente, ou seja, as personagens estão no passado, seus discursos estão no presente.

Desse modo, pode-se sustentar a ideia de que na série a memória é construída a partir do presente, na arena da confrontação. Em qualquer formação social, há muitas memórias que convivem (umas hegemônicas, outras marginais) e é a singularidade histórica, social e cultural que faz com que os sujeitos recordem de maneiras específicas, ou seja, a memória não está ali, esperando para ser contada. Paul Ricœur (2007) ressalta que o passado é o que não pode ser mudado, mas o que não é fixo é o significado do que aconteceu. Essa interpretação só pode se estabelecer no presente ou, melhor, nos sucessivos presentes nos quais a experiência é pensada. É exatamente essa flexibilidade na elaboração da memória que permite à série construir personagens feministas numa época em que o feminismo era ainda incipiente e, ao mesmo tempo, dar destaque a relações de classe que colocam inúmeras mulheres numa posição desigual. Essa dimensão fica explícita por meio da personagem Adélia. Já salientamos que ela é mãe solteira, porém sua filha é fruto de um relacionamento que teve com Nelson (Alexandre Cioletti), filho de sua patroa. A ideia de que a empregada também preste favores sexuais aos patrões é um hábito secular na sociedade brasileira, herança do período escravocrata em que as escravas, além de fazerem o trabalho doméstico, também mantinham relações sexuais com os senhores de engenho ou seus filhos. Após a gravidez, Adélia foi demitida e Nelson enviado a Paris por sua família, já que uma “criança mulata”, segundo a sua mãe (Esther Góes), não seria bem-vinda. 
Se, a partir da mídia, é possível dar sentido a uma certa experiência pela ativação da memória, ela só faz sentido quando se considera que "o lugar político das práticas de memória", como salienta Huyssen (2000, p. 17), "é ainda nacional e não pós-nacional”. Por esse motivo, direcionar o olhar para as nossas questões torna-se importante porque eles dizem respeito às nossas incertezas, conjunturas e modos de ser. Tão importante quanto isso é atentar para os materiais midiáticos e audiovisuais que a eles se reportam, como é o caso da série aqui em discussão. Essas demandas locais se tornam tão urgentes que a bossa nova, que a princípio poderia ser vista como uma questão central, fica para segundo plano, bem como o Rio de Janeiro como cenário. Em vez disso, novamente se fixa a mulher no centro das ações. Não à toa Thereza, ao se tornar editora-chefe de Ângela, muda o quadro de jornalistas da revista ao argumentar que "uma revista para mulheres deve ser escrita por mulheres". Não era esse o cenário do jornalismo brasileiro dos anos 1960, mas, numa espécie de licença poética, Coisa mais linda procura reforçar o poder feminino. Outro ponto sensível apresentado na série é o aborto. Quando decide seguir carreira como cantora, Lígia descobre que está grávida. Temendo que a maternidade atrapalhe os seus planos, ela decide por abortar e, para isso, conta com a ajuda da amiga Maria Luiza. Vemos que novamente a mulher coloca os seus desejos como prioridade. Um aspecto que, na década de 1960, seria pouco plausível, mas que, para balizar o discurso progressista da série, se institui como tal. Nesse caso, limitar-se ao verossímil impediria voos mais altos à série e comprometeria, em certa medida, a nossa análise.

Mas a nossa intenção não é estabelecer uma crítica aos moldes do jornalismo cultural, que apontaria, por exemplo, inconsistências no roteiro, mas perceber as potencialidades discursivas da série. Dentro dessa perspectiva, ao eleger quatro mulheres como protagonistas, e, mais importante, colocá-las na gerência de suas próprias vidas, Coisa mais linda volta ao passado para, acima de tudo, falar do presente - esse tempo em que, pelo menos no nosso contexto, tem sido cada vez mais marcado pelo debate que reivindica mais espaço e reconhecimento para a mulher na sociedade brasileira.

\section{Considerações Finais}

No Brasil, a Netflix se insere em um mercado tradicionalmente televisivo, em que a ficção é predominantemente nacional. Nesse contexto, a empresa passou a investir em produções originais, como estratégia não apenas de conquista de mercado interno mas também para expansão de fronteiras e atração de novas audiências. Es- 
sas narrativas, no geral, aparentam explorar as qualidades de uma 'brasilidade rentável', que retrate aspectos do Brasil para o mercado nacional, mas que tenha potencial de conquistar públicos estrangeiros.

Além destas dimensões midiáticas e de mercado, ressaltamos o fenômeno Netflix no que ele aponta sobre dimensões culturais da globalização (APPADURAI, 2004) em seus panoramas midiáticos, ideológicos e de constituição de imaginários globais, bem como nas noções mais amplas de cosmopolitismo aí esboçadas, para além de uma concepção elitista deste termo. Os sentidos de cosmopolitismo que aqui nos chamam a atenção são aqueles que salientam uma postura epistêmica e crítica (DELANTY, 2008) que interpreta os fenômenos a partir do "entre", ou seja, fugindo das dicotomias entre localismo e universalismo e assumindo o cosmopolitismo entre fluxos locais e globais, feitos a partir da negociação e disputa de sentidos. Nestas, os contatos materiais e imaginários com o Outro, seja presencialmente ou em telas, colaboram nos processos de transformação do mesmo a partir do contato com a alteridade.

É nesse cenário que uma série como Coisa mais linda se torna, então, possível. Ao apostar em dimensões locais (Rio de Janeiro, samba, bossa-nova), para dar conta de demandas que ultrapassam as fronteiras territoriais (o papel e a importância da mulher), a série estabelece uma negociação entre passado e presente que encontra na memória um importante aspecto. Isso permite que personagens que estão no passado sejam vistas como transgressoras no presente. Por meio delas, institui-se a discussão sobre questões de classe, gênero e raça - tão atuais nos dias de hoje. O debate em torno dessa articulação, do ponto de vista narrativo e enunciativo, nos leva a crer que o consumo midiático depende, em grande medida, da elaboração de narrativas que proponham outras subjetividades.

Neste contexto, as subjetividades ligadas às tecnicidades comunicativas merecem atenção, pois trazem importantes aspectos para refletir sobre a articulação complexa entre práticas de consumo, gostos coletivos e demais aspectos da vida cotidiana ajudando a construir "comunidades hermenêuticas de interpretação" (MARTÍN-BARBERO, 2004) que correspondem a novos modos de perceber e narrar as identidades cosmopolitas bem como suas formas de atribuição de sentido ao mundo.

\section{Notas:}

[1] A primeira telenovela brasileira a ser exportada foi $O$ Bem-Amado para países da América Latina, em 1976. Antes disso, apenas eram exportados os textos. Fonte: Memória Globo.

[2] Afetual é um neologismo utilizado na tradução de textos de Michel Maffesoli no Brasil e se refere aos aspectos de uma razão sensível salientada pelo autor como importante e fundamental elemento que se dá no cotidiano, aliado à estética, às socialidades e ao sentir em 
comum. Além disso, toda uma discussão sobre os afetos (numa dimensão espinoziana e deleuziana) e sua relevância para as ciências Humanas e Sociais, coadunadas no que tem sido denominado desde os anos 1990 de "affective turn", utilizam o termo afetual/afectual para se diferenciar do sentido comum de "afetivo". Utilizamos a noção de afetual aqui para ressaltar estas dimensões teórico-conceituais.

[3] No início da década de 1980 cerca de 3/4 da programação ficcional da TV já era nacional. Em 2012, esse índice chegou a 100\% (LOPES; OROZCO, 2013).

[4] Fonte: O Estado de São Paulo. Brasil já está entre os três principais mercados da Netflix. Entrevista com Erik Barmak, vice-presidente de conteúdo Internacional Netflix, em 15 de março de 2018.

[5] Fonte: O Estado de São Paulo. 'O brasileiro quer assistir a mais séries nacionais'. Entrevista com Erik Barmak, vice-presidente de conteúdo Internacional Netflix, em 20 de maio de 2018.

[6] 3\% - Criação: Pedro Aguilera. Direção: César Charlone, Daina Giannecchini, Dani Libardi e Jotagá Crema. Produtora: Boutique Filmes.

[7] O Mecanismo - Criação: José Padilha e Elena Soarez. Direção: José Padilha. Produtora: Zazen Produções.

[8] Samantha - Criação: Felipe Braga. Direção: Luís Pinheiro y Julia Jordão. Produtora: Los Bragas.

[9] Até março de 2019.

\section{Referências}

AMAYA, José Fernando Serrano. Menos querer más de la vida - concepciones de vida y muerte en jóvenes urbanos. Bogotá: Siglo del Hombre Editores, 2004.

APPADURAI, Arjun. Dimensões culturais da globalização. Lisboa: Teorema, 2004.

BENJAMIN, Walter. Teses sobre a filosofia da história - Tese II. In: KOTHE, Flávio R (org). Benjamin, Walter. Sociologia. São Paulo: Ática, 1985, p. 153-164.

BORGES, Gabriela. A discussão do conceito de qualidade no contexto televisual britânico. Bocc - Biblioteca Online de Ciências da Comunicação, 2008.

CASTELLANO, Mayka; MEIMARIDIS, Melina. Binge-Watching is the new black: as novas formas de espectatorialidade no consumo de ficção seriada televisiva. Contemporânea - Comunicação e Cultura .v.16, n.03, p. 689-707, 2018. Disponível em: < $\underline{\text { https:// }}$ portalseer.ufba.br/index.php/contemporaneaposcom/article/view/24572>. Acesso em: 7 abr. 2020.

DELANTY, Gerard.Laimaginación cosmopolita. Revista CIDOBd'Afers Internacionals, n. 82, p. 25-49, 2008. Disponível em: < https://www.cidob.org/es/articulos/revista cidob_d_afers_internacionals/la_imaginacion_cosmopolita $>$. Acesso em: 7 abr. 2020. 
DOUGLAS, Mary; ISHERWOOD, Baron. O mundo dos bens: para uma antropologia do consumo. Rio de Janeiro: Ed. UFRJ, 2004.

GARCÍA CANCLINI, Nestor. Consumidores e cidadãos - conflitos multiculturais da Globalização. Rio de Janeiro: Ed. UFRJ, 2004.

GIDDENS, Anthony. Modernity and self-identity: self and society in the late modern age. Stanford: Stanford University Press, 1999.

HANNERZ, Ulf. Cosmopolitas e locais na cultura global. In FEATHERSTONE, Mike (ed.). Cultura global: nacionalismo, globalização e modernidade. Petrópolis: Vozes, 1999, p.251-266.

HUYSSEN, Andreas. Seduzidos pela memória: arquitetura, monumentos, mídia. Rio de Janeiro: Aeroplano, 2000.

JENKINS, Henry. Cultura da convergência. São Paulo: Aleph, 2008.

JOLY, Martine. Introdução à análise da imagem. Campinas: Papirus, 1996.

JOST, François. Analisar a televisão. In: GARDIES, René (org.). Compreender o cinema e as imagens. Lisboa: Texto e Grafia, 2008, p. 191-207.

LOPES, Maria Immacolata Vassallo de; GRECO, Clarice. Brasil: dinâmicas da ficção televisiva na transição multicanal. In: LOPES, Maria Immacolata Vassallo de; OROZCO GÓMEZ, Guillermo (org.). Ficção televisiva Ibero- Americana em plataformas de video on demand. Porto Alegre: Sulina, 2018, p. 103-134.

LOPES, Maria Immacolata Vassallo. Telenovela: Internacionalização e Interculturalidade. São Paulo: Loyola, 2004.

LOPES, Maria Immacolata Vassallo. A Telenovela Brasileira: uma Narrativa Sobre a Nação. Comunicação \& Educação, v.26, p.17-34, 2003. Disponível em: < $\underline{\text { http://www. }}$ revistas.usp.br/comueduc/article/view/37469>. Acesso em 07 abr. 2020.

MACDOUGALL, David. Transcultural cinema. Princeton: Princeton University Press, 1998.

McCracken, Grant. Cultura e consumo. Rio de Janeiro: Ed. Mauad, 2003.

MARTÍN-BARBERO, Jesús. Ofício de cartógrafo: travessias latino-americanas da comunicação na cultura. São Paulo: Loyola, 2004.

RICOEur, Paul. A memória, a história, o esquecimento. Campinas: Ed. Unicamp, 2007.

SACCOMORI, Camila. Qualquer coisa a qualquer hora em qualquer lugar: as novas experiências de consumo de seriados via Netflix. Revista Temática, v. 11, n.4, p. 53- 
68, 2005. Disponível em: $<$ https://periodicos.ufpb.br/ojs/index.php/tematica/article/ view/23903>. Acesso em: 7 abr. 2020.

SILVA, Marcel Vieira Barreto. Cultura das séries: forma, contexto e consumo de ficção seriada na contemporaneidade. Galaxia, n. 27, p. 241-252, 2014. Disponível em: $<$ https://revistas.pucsp.br/index.php/galaxia/article/view/15810>. Acesso em 07 abr. 2020.

STRAUBHAAR, Joseph. Brazilian Television: the decline of American influence. Communication Research, v. 11, n. 2, p. 221-240, 1984. Disponível em: $<$ https://journals. sagepub.com/doi/abs/10.1177/009365084011002006 >. Acesso em 07 abr. 2020.

TOALDO, Mariângela; JACKS, Nilda "Consumo midiático: uma especificidade do consumo cultural, uma antesala para os estudos de recepção". Anais... Encontro Anual da Compós - Associação Nacional dos Programas de Pós-Graduação em Comunicação. Salvador (BA), Junho 2013. Disponível em: < http://www.compos.org.br/ data/biblioteca_2115.pdf $>$. Acesso em: 7 abr. 2020.

WOLTON, Dominique. O Elogio do Grande Público. Uma teoria crítica da televisão. São Paulo: Ática, 1996. 